\title{
Supercritical Fluid Extraction of Quinones from Compost for Microbial Community Analysis
}

\author{
Ni Luh Gede Ratna Juliasih,, ${ }^{1,2}$ Lee Chang Yuan, ${ }^{1}$ Yuki Sago, \\ Yoichi Atsuta, ${ }^{1}$ and Hiroyuki Daimon ${ }^{1,4}$ \\ ${ }^{1}$ Department of Environmental and Life Sciences, Toyohashi University of Technology, Aichi 441-8180, Japan \\ ${ }^{2}$ Department of Chemistry, Lampung University, Lampung 35145, Indonesia \\ ${ }^{3}$ Faculty of Agriculture, Yamaguchi University, Yamaguchi 753-8511, Japan \\ ${ }^{4}$ Center for International Relations, Institute for Global Network Innovation in Technology Education, \\ Toyohashi University of Technology, Aichi 441-8180, Japan \\ Correspondence should be addressed to Hiroyuki Daimon; daimon@ens.tut.ac.jp
}

Received 20 May 2015; Revised 13 August 2015; Accepted 16 August 2015

Academic Editor: Jaime Villaverde

Copyright (C) $2015 \mathrm{Ni}$ Luh Gede Ratna Juliasih et al. This is an open access article distributed under the Creative Commons Attribution License, which permits unrestricted use, distribution, and reproduction in any medium, provided the original work is properly cited.

\begin{abstract}
Supercritical fluid extraction (SFE) was used to extract quinones from compost to monitor the microbial community dynamics during composting. The $0.3 \mathrm{~g}$ of dried compost was extracted using $3 \mathrm{~mL} \mathrm{~min}^{-1}$ of carbon dioxide (90\%) and methanol $(10 \%)$ at $45^{\circ} \mathrm{C}$ and $25 \mathrm{MPa}$ for a $30 \mathrm{~min}$ extraction time. The extracted quinones were analysed using ultra performance liquid chromatography (UPLC) with $0.3 \mathrm{~mL} \mathrm{~min}^{-1}$ of methanol mobile phase for a $50 \mathrm{~min}$ chromatographic run time. A comparable detected amount of quinones was obtained using the developed method and an organic solvent extraction method, being $36.06 \mu \mathrm{mol} \mathrm{kg} \mathrm{g}^{-1}$ and $34.54 \mu \mathrm{mol} \mathrm{kg}^{-1}$, respectively. Significantly low value of dissimilarity index $(D)$ between the two methods (0.05) indicated that the quinone profile obtained by both methods was considered identical. The developed method was then applied to determine the maturity of the compost by monitoring the change of quinone during composting. The UQ-9 and MK-7 were predominant quinones in the initial stage of composting. The diversity of quinone became more complex during the cooling and maturation stages. This study showed that SFE had successfully extracted quinones from a complex matrix with simplification and rapidity of the analysis that is beneficial for routine analysis.
\end{abstract}

\section{Introduction}

Composting is a proven and effective method for the conversion of organic waste into valuable products that can be used in agriculture. Compost can improve the physical and chemical properties of the soil and the production of crops $[1,2]$. Nevertheless, in some cases, the utilization of immature compost may generate destructive effects, including delay in germination and inhibition of grain yield $[3,4]$. Therefore, the maturity of compost is essential for the soil environment and the crop production.

Since the microbial community plays an important role in composting, the evaluation of compost maturity based on it has attracted increased focus $[1,5]$. One of the convenient methods for the assessment of microbial community is the quinone profile method due to its simplicity, quantitative and high repeatability $[1,6-8]$. The quinone profile method is used to evaluate the microbial community in the environment based on the changes in quinone profile. Understanding the change of the quinone profile enables characterization of the microbial community dynamics. In general, one species or genus of microbial community has only one dominant type of quinones $[1,9,10]$. The identification of classes of quinones provides a snapshot of the diversity of microbes present. Therefore, a quinone profile could represent the microbial community structure during composting.

Quinone is one of the components of the electron transport chain in microbial cells, classified into two major groups: 
ubiquinone (UQ, 1-methyl-2-isoprenyl-3,4-dimethoxyparabenzoquinone) and menaquinone (MK, 1-isoprenyl-2-methyl-naphthol-quinone). In the nomenclature of quinones, a dash and a number represent the isoprenoid units of its side chain $[9,10]$.

Quinone determination consists of the extraction of quinones from the matrix and analysis using high performance liquid chromatography (HPLC) $[8,11]$. Organic solvent extraction using a mixture of chloroform and methanol has been used as a sample preparation for extracting quinones $[8$, 11]. However, the procedure is tedious and time consuming. Moreover, this method requires a large quantity of organic solvent.

In order to overcome these disadvantages, a sample preparation with supercritical fluid extraction (SFE) has been developed $[12,13]$. SFE has been successfully used as an effective, rapid, and quantitative extraction technique for quinones from activated sludge samples [12, 13]. Irvan et al. reported that the optimum conditions for extraction of quinones from activated sludge were at a pressure of $25 \mathrm{MPa}$, a temperature of $55^{\circ} \mathrm{C}$, and $10 \%(\mathrm{v} / \mathrm{v})$ methanol for a $15 \mathrm{~min}$ extraction time [12]. Hanif et al. investigated the effects of different trapping systems in SFE and ultra performance liquid chromatography (UPLC) on the total content of extracted quinones from activated sludge. They discovered that SFE, with a solid-phase cartridge trap, proved to be a more rapid and effective method for extracting respiratory quinones, compared to a conventional organic solvent extraction method. The method could significantly reduce the complexity in the procedure and time required for sample preparation [13].

In this study, the SFE was used to extract quinones from commercial compost of food waste and wood chips, as a substitute for organic solvent extraction. Since the compost contained a more complex matrix that might make the extraction of quinones difficult, the extraction conditions including the extraction time and temperature were examined to obtain optimized conditions. The method was validated by comparing the quinone profile with those obtained from an organic solvent extraction method. Furthermore, this method was then used to determine the quinone profile for daily monitoring of the composting process.

\section{Experimental}

2.1. Materials and Standard Solutions. The standards used in this study were ubiquinone-10 (UQ-10) and menaquinone7 (MK-7), purchased from Nacalai Tesque (Kyoto, Japan). Chloroform, hexane, diethyl ether, acetone, diisopropyl ether, and methanol were HPLC grade obtained from Wako Co. (Osaka, Japan). The Sep-Pak Plus Silica cartridges (10 mm id $\times 20 \mathrm{~mm}$, packed with $600 \mathrm{mg}$ of silica gel with particle diameter of $55-105 \mu \mathrm{m})$ were purchased from the Waters Co. (Milford, MA, USA). The Chromafil $\Phi$ 20/15 MS (pore size $0.20 \mu \mathrm{m}$ and a diameter of $15 \mathrm{~mm}$ ) was obtained from Macherey-Nagel (Düren, Germany).

2.2. Sample Pretreatment. The sample used in this study was provided by the Komasuya Composting Company, located

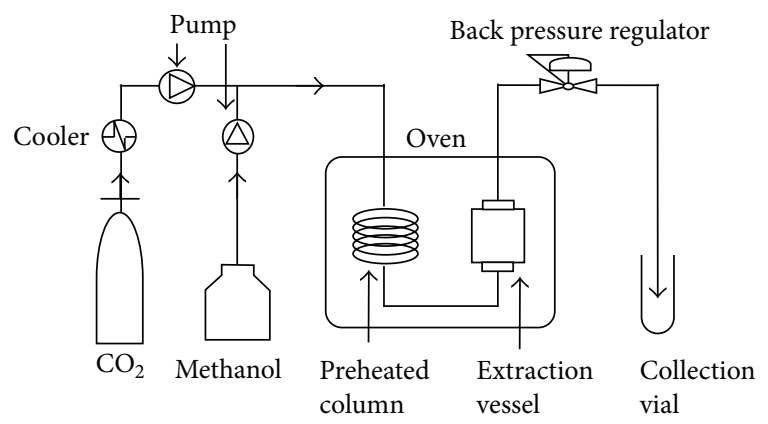

FIGURE 1: Schematic diagram of supercritical fluid extraction (SFE) apparatus for quinones extraction.

in Toyota City, Aichi Prefecture, Japan. It is a commercial full scale composting site which produces 3250-ton compost/ month, consisting of a mixture of food waste $(50 \% \mathrm{v} / \mathrm{v})$ and wood chips. Prior to quinones analysis, the samples were dried in a vacuum-freeze dryer for $24 \mathrm{~h}$, crushed, and then sieved to collect particles smaller than $500 \mu \mathrm{m}$. Freeze dried compost samples were stored at $-30^{\circ} \mathrm{C}$ until analysis. Approximately $0.3 \mathrm{~g}$ of freeze dried compost sample was used in each extraction experiment.

2.3. Determination of $\mathrm{C} / \mathrm{N}$ Ratio. The $\mathrm{C} / \mathrm{N}$ ratio represents the relative proportion of the carbon and nitrogen. The $\mathrm{C} / \mathrm{N}$ ratio has been used to evaluate the maturity and stability of compost [14]. The determination of $\mathrm{C} / \mathrm{N}$ ratio was conducted by analyzing the dried samples for total carbon and total nitrogen using a CHN analyser (Vario EL III Element Analyzer, Elementar Analysensysteme GmbH, Hanau, Germany).

2.4. Supercritical Fluid Extraction. The extractions were performed using the SFE system, as shown in Figure 1. This system consists of a cooler (Scinics CH-201, Tokyo, Japan), pumps (PU-1580 HPLC and PU-2086 HPLC, Jasco, Tokyo, Japan), a preheated column $(0.25 \mathrm{~mm}$ id $\times 1.59 \mathrm{~mm}$ od $\times$ $2 \mathrm{~m}$ ), an oven (GC-353B, GL Sciences, Tokyo, Japan), and a back pressure regulator (BPG 880-81, Jasco). A freeze dried compost sample was then placed in a $1 \mathrm{~mL}$ stainless steel extraction vessel (SUS316, Jasco).

The extractions were conducted in dynamic mode. Carbon dioxide $\left(\mathrm{CO}_{2}\right)$ used as an extraction solvent at a flow rate of $2.7 \mathrm{~mL} \mathrm{~min}{ }^{-1}$ and methanol as a modifier at $0.3 \mathrm{~mL} \mathrm{~min}^{-1}$ were continuously mixed in the line to extract the quinones from the compost sample. The extracted quinones were purified, as described elsewhere [12]. The hexane extract was loaded into the Sep-Pak Plus Silica cartridge and the Chromafil before quantification on UPLC. Triplicate experiments were carried out to determine the precision of all experiments.

2.5. Organic Solvent Extraction. Organic solvent extraction was also carried out to extract the quinones from the compost sample using a procedure as described elsewhere $[8,11]$. The $0.3 \mathrm{~g}$ of freeze dried compost sample was used in each extraction experiment as in the SFE method. 
2.6. Ultra Performance Liquid Chromatography Analysis. The Waters Acquity UPLC system (Milford, MA, USA) that is equipped with a binary solvent delivery manager, a sample manager, and a photodiode array detector (PDA-2996, Waters) was used for the quantification of quinones during all parts of the study. A Waters Acquity UPLC BEH C18 column $(2.1 \mathrm{~mm}$ id $\times 50 \mathrm{~mm}$, particle size $1.7 \mu \mathrm{m})$ was used as the analytical column. Methanol was used for the mobile phase with a flow rate at $0.3 \mathrm{~mL} \mathrm{~min}^{-1}$. The analysis was performed at $35 \pm 1^{\circ} \mathrm{C}$ with a chromatographic run time of $50 \mathrm{~min}$. The autosampler temperature was set at $4.0 \pm 1^{\circ} \mathrm{C}$ and the sample injection volume was $10 \mu \mathrm{L}$ [13].

The ubiquinone and menaquinone species were identified based on the retention time on the column and the spectrum of each peak observed in the PDA detector at $270 \mathrm{~nm}$ for MKs and at $275 \mathrm{~nm}$ for UQs. The PDA detector is a multichannel UV detector that facilities the accurate determination of quinones composition [7].

The linier correlation between the logarithm of retention time of quinones and an equivalent number of isoprenoid units (ENIU) was used to identify the quinones species [15]. UQ-10 and MK-7 were used as quantitative standards for UQ and MK, respectively. The ENIU can be approximated by the following equation:

$$
\mathrm{ENIU}_{k}=a+b \log \left(\frac{\mathrm{ET}_{k}}{\mathrm{ET}_{\text {std }}}\right)+c\left[\log \left(\frac{\mathrm{ET}_{k}}{\mathrm{ET}_{\text {std }}}\right)\right]^{2},
$$

where $\mathrm{ET}_{k}$ represents the elution time of a quinone species $k$ and $\mathrm{ET}_{\text {std }}$ represents the elution time of standard quinone. The constants are shown as $a, b$, and $c$, which are empirically obtained for each UPLC system [15]. The amounts of quinones were calculated from the peak area based on the mole absorption coefficients (ubiquinone $14.4 \mathrm{mM}^{-1} \mathrm{~cm}^{-1}$, menaquinone $17.4 \mathrm{mM}^{-1} \mathrm{~cm}^{-1}$ ) [16]. The quinones mole fraction was calculated as a ratio of the quinones content in the species $k$ to the total quinones content.

\section{Results and Discussion}

3.1. Effect of Extraction Temperature on the Detected Amount of Quinones from the Compost. Extraction temperature is one of the essential parameters in SFE with respect to the complexity of the matrix in the compost and decomposition of quinones. In this study, the effect of extraction temperature was examined at a constant pressure of $25 \mathrm{MPa}$ over a temperature range from $35^{\circ} \mathrm{C}$ to $55^{\circ} \mathrm{C}$, using $\mathrm{CO}_{2}$ for solvent extraction at a flow rate of $2.7 \mathrm{~mL} \mathrm{~min}^{-1}$ and methanol as a modifier at a flow rate of $0.3 \mathrm{~mL} \mathrm{~min}^{-1}$ for a 30 min extraction time. Figure 2 shows the effect of the extraction temperature on the detected amount of quinones from compost. The results showed that the detected amount of quinones was highest at a temperature of $45^{\circ} \mathrm{C}$.

The increase of extraction temperature at the constant pressure causes an enhancement in diffusivity and $\mathrm{CO}_{2}$ vapor pressure which increases the solubility of the quinones. When the extraction temperature was higher than $45^{\circ} \mathrm{C}$, the detected amount of quinones decreased due to the decomposition of quinones at temperatures above $45^{\circ} \mathrm{C}$. Based on

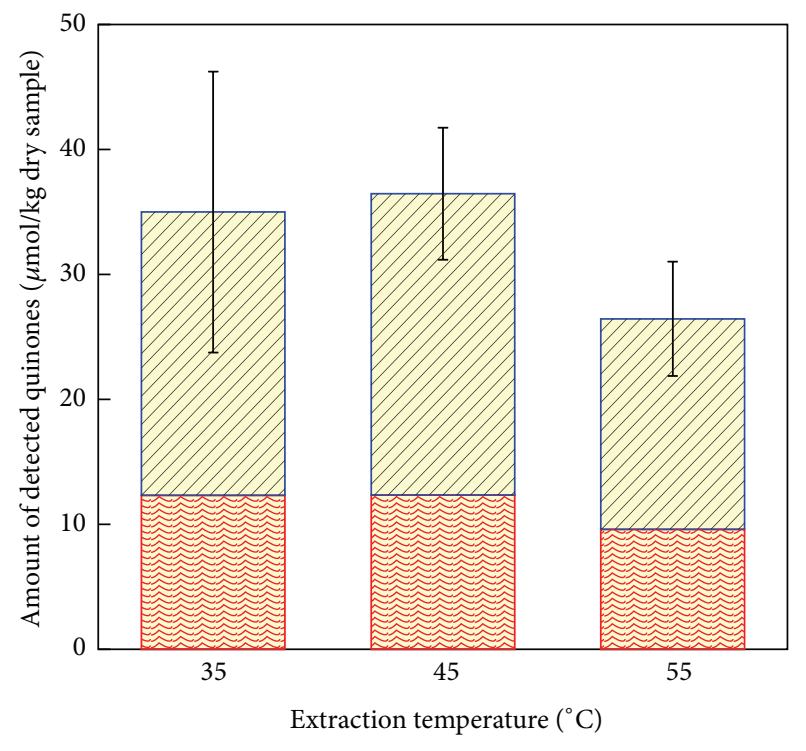

DIA MK

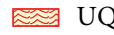

FIGURE 2: Detected amount of quinones obtained on different extraction temperature. Sample: $0.3 \mathrm{~g}$ dry compost of food waste and wood chips. SFE conditions: $25 \mathrm{MPa} ; 90 \% \mathrm{CO}_{2}-10 \%$ methanol; flow rate of $3 \mathrm{~mL} \mathrm{~min}^{-1} ; 30 \mathrm{~min}$; number of samples examined $=3$.

the results shown in Figure 2, a temperature of $45^{\circ} \mathrm{C}$ was the optimum temperature over the examined temperature range because the detected amount of quinones was highest and the error bar was relatively small, due to the minimal loss of quinones during the extraction. Therefore, a temperature of $45^{\circ} \mathrm{C}$ is considered as the most appropriate temperature to extract quinones from compost.

\subsection{Effect of Extraction Time on the Detected Amount of} Quinones from the Compost. Compost contains a complex matrix which might provide difficulty in the process and that requires extra energy to extract quinones from compost. Therefore, the extraction time is another crucial parameter in SFE. Varied extraction times between 10 and $40 \mathrm{~min}$ were evaluated to determine the suitable extraction time for quinones from compost with SFE. Figure 3 shows the detected amount of quinones at a different extraction time.

A comparable detected amount of quinones was obtained at an extraction time of $20 \mathrm{~min}, 30 \mathrm{~min}$, and $40 \mathrm{~min}$. However, at the shorter extraction time, a high error bar was obtained. This may be due to the inhomogeneous nature of the system. When the extraction time was increased to $30 \mathrm{~min}$, the balance of extraction was reached to enable extraction of the analytes. At the extraction time of $40 \mathrm{~min}$, the high error bar might be caused by the increased amount of $\mathrm{CO}_{2}$ released from the restrictor, which could lead to higher quinones losses. Therefore the extraction time of $30 \mathrm{~min}$ was selected as the optimum extraction time to extract quinones from a $0.3 \mathrm{~g}$ freeze dried compost sample under the tested conditions. In addition, using an extraction time of $30 \mathrm{~min}$ will reduce energy usage when compared to an extraction time of $40 \mathrm{~min}$. 


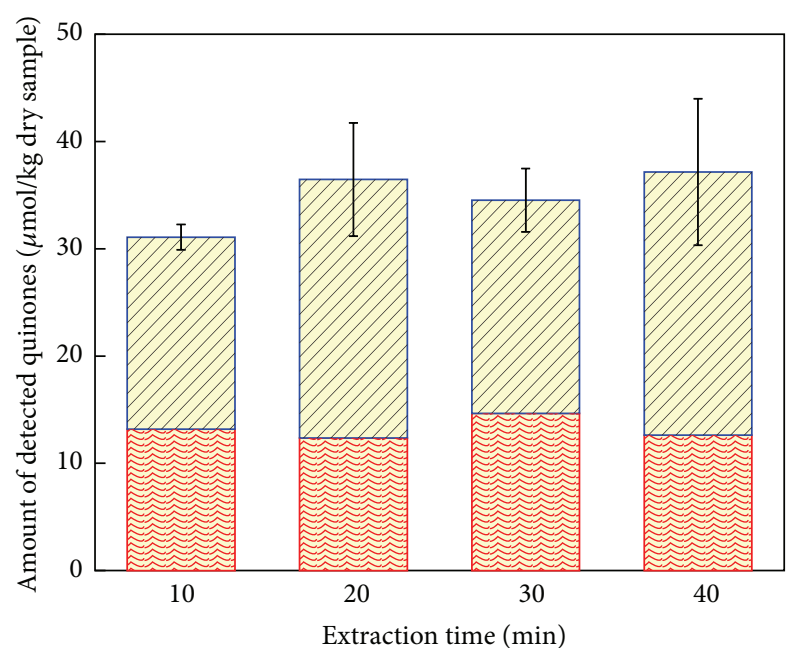

$\begin{array}{ll}\text { MI } & \text { MK } \\ \text { E्त्र } & \text { UQ }\end{array}$

FIGURE 3: Detected amount of quinones obtained in different extraction time periods. Sample: $0.3 \mathrm{~g}$ dry compost of food waste and wood chips. SFE conditions: $25 \mathrm{MPa} ; 90 \% \mathrm{CO}_{2}-10 \%$ methanol; flow rate of $3 \mathrm{~mL} \min ^{-1} ; 45^{\circ} \mathrm{C}$; number of samples examined $=3$.

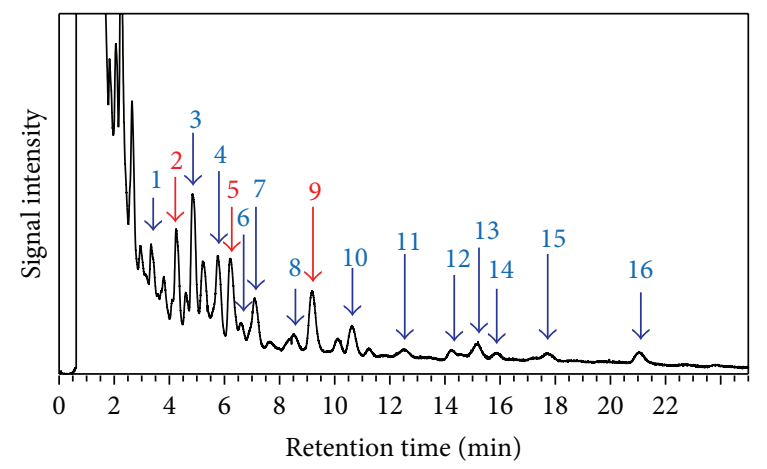
(1) MK-6
(10) MK-9
(2) UQ-8
(11) MK-9 $\left(\mathrm{H}_{2}\right)$
(3) MK-7
(12) MK-9 $\left(\mathrm{H}_{4}\right)$
(4) $\mathrm{MK}-7\left(\mathrm{H}_{2}\right)$
(13) MK-10
(5) UQ-9
(14) MK-9 $\left(\mathrm{H}_{6}\right)$
(6) MK-7 $\left(\mathrm{H}_{4}\right)$
(15) $\mathrm{MK}-10\left(\mathrm{H}_{4}\right)$
(7) MK-8
(16) $\mathrm{MK}-10\left(\mathrm{H}_{8}\right)$
(8) $\mathrm{MK}-8\left(\mathrm{H}_{2}\right)$
(9) UQ-10

FIgURE 4: Chromatogram of quinones obtained from compost by SFE and UPLC. Sample amount: $0.3 \mathrm{~g}$ dried compost. SFE conditions: $45^{\circ} \mathrm{C}$; $25 \mathrm{MPa}$; $15 \mathrm{~min}$; $90 \% \mathrm{CO}_{2}-10 \%$ methanol with flow rate of $1 \mathrm{~mL} \mathrm{~min}^{-1}$. UPLC conditions: column: $2.1 \times 30 \mathrm{~mm}, 1.7 \mu \mathrm{m}$ Acquity $\mathrm{BEH} \mathrm{C18}$ at $35^{\circ} \mathrm{C}$; methanol mobile phase at flow rate of $0.3 \mathrm{~mL} \mathrm{~min}^{-1} ; 10 \mu \mathrm{L}$ sample injection volume, PDA.

The chromatogram of quinones obtained from compost sample by SFE and UPLC is shown in Figure 4.

3.3. Comparison of Quinone Profile between SFE and Organic Solvent Extraction Method. The detected amount of quinones obtained by SFE based on the optimized conditions was

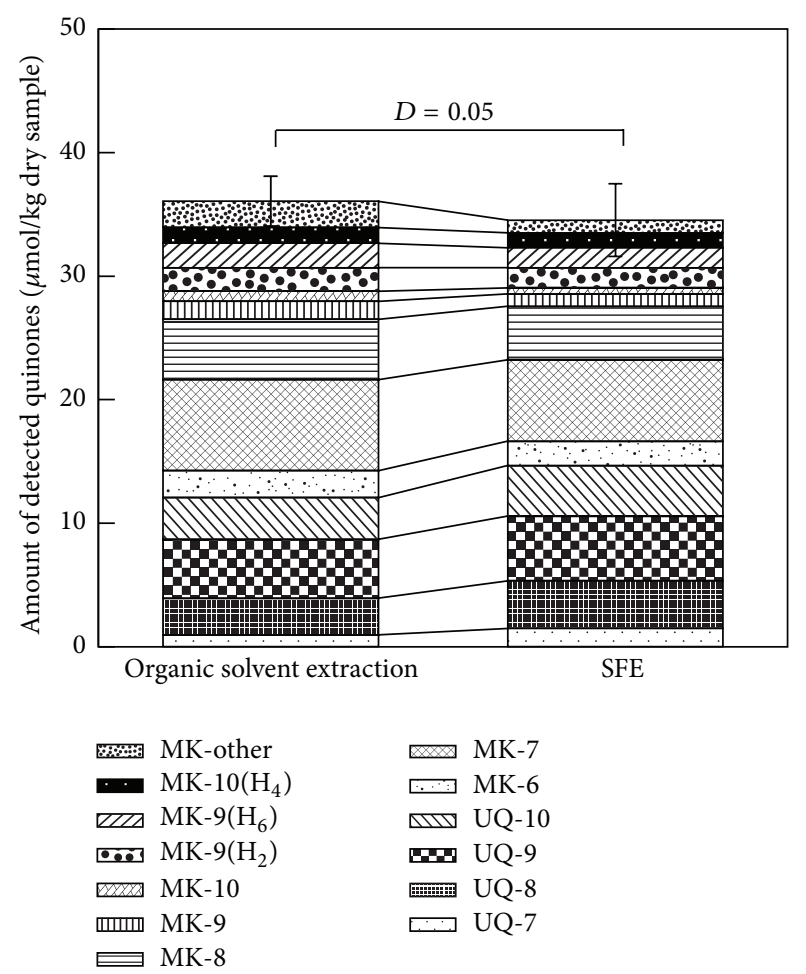

FIgURE 5: Comparisons of quinone profile between the SFE and organic solvent extraction methods. Sample: $0.3 \mathrm{~g}$ dry compost of food waste and wood chips for both methods. Organic solvent extraction conditions: chloroform : methanol $=2: 1(20 \mathrm{~mL}) ; 15 \mathrm{~h}$. SFE conditions: $25 \mathrm{MPa}$; $90 \% \mathrm{CO}_{2}-10 \%$ methanol, flow rate of

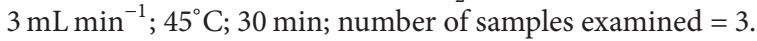

compared to those obtained by the organic solvent extraction method using the dissimilarity index $(D)$ value; it is the number that indicated the degree of differences in quinones patterns between the samples. It is calculated by an equation as follows: $D_{(i, j)}=(1 / 2) \sum_{k=1}^{n}\left|f_{k i}-f_{k j}\right|$, where $f_{k i}$ and $f_{k j}$ are molar fractions of quinones species $k$ for samples $i$ and $j$, respectively. Two quinone profiles are considered to be different if the value of $D$ between them is equal to or greater than 0.1 [7]. In these experiments, the low value of $D(0.05)$ indicates that the quinone profile obtained by both methods was similar.

Both the SFE and the organic solvent extraction method were conducted three times for each $0.3 \mathrm{~g}$ freeze dried compost sample. Four types of UQs (UQ-7, UQ-8, UQ-9, and UQ-10) and nine types of MKs (MK-6, MK-7, MK-8, MK-9, MK-10, MK-9 $\left(\mathrm{H}_{2}\right)$, MK-10 $\left(\mathrm{H}_{4}\right)$, MK-9 $\left(\mathrm{H}_{6}\right)$, and MK-other) were obtained by using the two methods. The predominance of MK-7 in compost was also confirmed by another author $[1,6]$.

The amount and the composition of each of the quinone species obtained by the two methods are shown in Figure 5. The total detected amounts of quinones obtained by SFE and organic solvent extractions were $34.54 \mu \mathrm{mol} \mathrm{kg}^{-1}$ dry sample and $36.06 \mu \mathrm{mol} \mathrm{kg}{ }^{-1}$ dry sample, respectively. These results showed that the detected amount of quinones by both methods was comparable. The detected amount of quinones 
was usually varied $[1,17]$ depending on the composition of the raw materials and the conditions for the composting. Therefore, there are no particular tendencies on the detected amount of quinones in composting.

The comparable values of the detected amount of quinones and low value of $D$ showed that the development of SFE can substitute the organic solvent extraction method with one that is faster, has a lower cost, and uses organic solvent. Furthermore, this simplified method is suitable for routine analysis with a large number of samples. In this study, the SFE was used for monitoring the quinone profile in the composting of food waste and wood chips.

3.4. Changing of the Quinone Profile during Composting from Food Waste and Wood Chips. The correlation between the changing of the quinone profile with the temperature and $\mathrm{C} / \mathrm{N}$ ratio during composting of food waste and wood chips is shown in Figure 6. The composting was divided into an initial phase with a rapidly increasing temperature, a second phase with a higher temperature, and a cooling process as the final phase. According to the company that provided samples for this study, during the initial and the second phase of composting, the raw materials were turned once a week without aeration supply. In addition, on the second phase, the material was moved into several small outdoor piles. The aeration was applied after ten weeks of composting when the material moved into several small indoor composting areas before it was finally packed.

As shown in Figure 6, the temperature increased from the first week of composting to as high as $65^{\circ} \mathrm{C}$, while the $\mathrm{C} / \mathrm{N}$ ratio decreased from 28 to 22.5 . The increase in temperature and the decrease of the $\mathrm{C} / \mathrm{N}$ ratio were correlated to the activities of the microbial community in the degradation of organic matters $[17,18]$. On the other hand, the detected amount of quinones increased and reached maximum in the 4th week of composting, which shows the growth of the microbial community to decompose the easily decomposable organic matter. The predominant quinones at this stage were MK-7 (20.5\%), followed by UQ-9 (13.1\%) and UQ-10 (12.5\%). Several studies have reported that the microbial community of Proteobacteria was the common microbial community in the initial phase of composting and that Proteobacteria was known to contain the types UQ-9 and UQ-10 [6, 17]. The increasing temperature, the decreasing $\mathrm{C} / \mathrm{N}$ ratio, and the presence of those types of quinones on this stage were also found in other studies, indicating that composting in this study was working properly $[1,19]$. In addition, it shows that the developed quinones analysis was acceptable for composting monitoring.

In the second phase, the temperature rises $70^{\circ} \mathrm{C}$ in the 8th week of composting. In order to maintain the increasing temperature, the material was moved into a smaller pile to ensure a sufficient oxygen supply. The tendencies of the $\mathrm{C} / \mathrm{N}$ ratio decreased, which is in agreement with other studies [20-22]. The detected amount of quinones was gradually decreased which indicated a decrease of biomass. The changes of biomass and quinone profile were caused by a change in composting conditions, particularly the temperature and oxygen amount. The major quinone in this stage was MK-7,
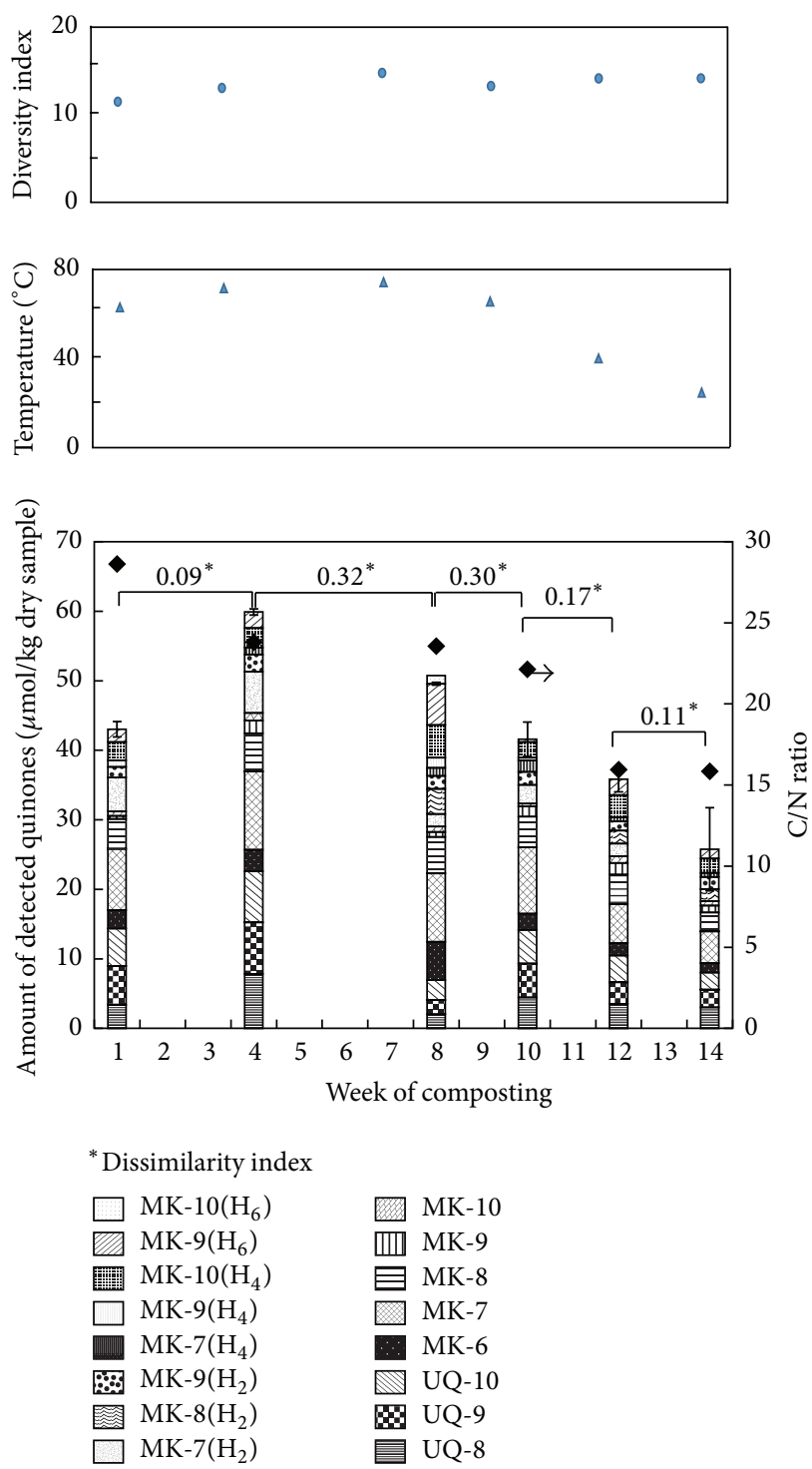

Figure 6: Changes of the quinone profile, $\mathrm{C} / \mathrm{N}$ ratio, temperature, and diversity index of compost from food waste and wood chips. The number represents the dissimilarity index of the quinones profile. Number of samples examined $=3$.

which is in agreement with other studies $[1,6,19]$. Other studies report the microbial community structure from a genus of Bacillus where common bacteria exist at high temperatures in composting which is known to contain MK-7 as the major quinone $[1,6,19]$.

The final phase of composting was characterized by a gradual decrease of temperature to $40^{\circ} \mathrm{C}$ and the temperature of the compost product reaching $28^{\circ} \mathrm{C}$. The $\mathrm{C} / \mathrm{N}$ ratio was 15.9 by the end of composting. In this stage, aeration was applied to stabilize the quality of the product. The detected amount of quinones decreased with the more complex profile. The gradual decrease in the detected amount of MK-7 could be an indication of the succession of the microbial community. The increase in the detected amount of $\operatorname{MK} 8\left(\mathrm{H}_{2}\right)$, MK-9 $\left(\mathrm{H}_{6}\right)$, MK-10 $\left(\mathrm{H}_{4}\right)$, and some other 
MK-n $\left(H_{x}\right)$ was also found in this phase which suggested that these types of quinones played an important role during the degradation of remaining organic matters in composting. The tendencies of temperature decrease and $\mathrm{C} / \mathrm{N}$ ratio which were accompanied by an increase in the complexity of the quinone profile obtained in this study are considered to be the maturation of compost since the evidence was similar to those studied elsewhere $[6,17,19]$. Therefore, the physical and chemical properties of compost were significantly related to the microbial community and the microbial community could be characterized by the quinone profile analysis that was performed by the developed method.

The dissimilarity index $(D)$, which quantitatively indicates a change in the quinone profile between samples, showed that the value of $D$ from the 1st to 4 th week of composting was low. This means that the types of quinones were not significantly changed for the easily decomposable organic matter. However, the value of $D$ was high from the 4 th to 8 th week and also from the 8th to the 10th week of composting, which shows the significant change in the microbial community due to the changing of the physical and chemical properties of composting. At the maturation of compost, the value of $D$ was low which indicated the stability of the microbial community.

The complexity of quinones defined by diversity index $(D Q)$ value is calculated using the following equation: $D Q=$ $\left(\sum_{k=1}^{n} \sqrt{f_{k}}\right)^{2}$ [7]. $f_{k}$ is the mole fraction of $k$ quinones species and $n$ is the number of quinones species. As shown in Figure 6, DQ in the initial phase of composting was 11.8 and reached a value of more than 13 at the final phase. This indicated that the microbial community structure was developed to be more complex at the mature stage. These results were also confirmed with the previous studies, in which microbial diversity increases during the cooling and maturation stage of composting $[6,17]$.

\section{Conclusion}

The SFE and UPLC offer simplification for a rapid and routine analysis such as monitoring the conditions of composting based on quinone profile. In this study, SFE and UPLC had successfully determined the quinone profile for microbial community analysis during composting. The comparison of this method and the conventional organic solvent extraction method, with the indication of dissimilarity index, showed that this method should be considered as a substitute of the organic solvent extraction method. Since the SFE and UPLC could be used as an alternative method, the assessment of microbial community dynamics in compost should be more fully covered in future studies to collect more information in the evaluation of the maturity of compost.

\section{Conflict of Interests}

The authors declare that there is no conflict of interests regarding the publication of this paper.

\section{Acknowledgments}

The sample compost used in this work was prepared by Komasuya Co. Ltd. (Nagoya, Japan) and this work was financially supported by A-step funding program from Japan Science and Technology Agency (JST).

\section{References}

[1] J.-C. Tang, Y. Inoue, T. Yasuta, S. Yoshida, and A. Katayama, "Chemical and microbial properties of various compost products," Soil Science and Plant Nutrition, vol. 49, no. 2, pp. 273-280, 2003.

[2] E. Ouédraogo, A. Mando, and N. P. Zombré, "Use of compost to improve soil properties and crop productivity under low input agricultural system in West Africa," Agriculture, Ecosystems and Environment, vol. 84, no. 3, pp. 259-266, 2001.

[3] P. Bazzoffi, S. Pellegrini, A. Rocchini, M. Morandi, and O. Grasselli, "The effect of urban refuse compost and different tractors tyres on soil physical properties, soil erosion and maize yield," Soil \& Tillage Research, vol. 48, no. 4, pp. 275-286, 1998.

[4] F. Kutsanedzie, G. N. K. Rockson, E. D. Aklaku, and S. Achio, "Comparisons of compost maturity indicators for two field scale composting system," International Research Journal of Applied Basic Sciences, vol. 3, pp. 713-720, 2012.

[5] H.-Y. Zhao, J. Li, J.-J. Liu, Y.-C. Lü, X.-F. Wang, and Z.-J. Cui, "Microbial community dynamics during biogas slurry and cow manure compost," Journal of Integrative Agriculture, vol. 12, no. 6, pp. 1087-1097, 2013.

[6] H. Yu, G. Zeng, H. Huang et al., "Microbial community succession and lignocellulose degradation during agricultural waste composting," Biodegradation, vol. 18, no. 6, pp. 793-802, 2007.

[7] A. Hiraishi, "Isoprenoid quinones as biomarkers of microbial populations in the environment," Journal of Bioscience and Bioengineering, vol. 88, no. 5, pp. 449-460, 1999.

[8] F. Kurisu, H. Satoh, T. Mino, and T. Matsuo, "Microbial community analysis of thermophilic contact oxidation process by using ribosomal RNA approaches and the quinone profile method," Water Research, vol. 36, no. 2, pp. 429-438, 2002.

[9] M. D. Collins and D. Jones, "Distribution of isoprenoid quinone structural types in bacteria and their taxonomic implications," Microbiological Reviews, vol. 45, no. 2, pp. 316-354, 1981.

[10] D. B. Hedrick and D. C. White, "Microbial respiratory quinones in the environment: I. A sensitive liquid chromatographic method," Journal of Microbiological Methods, vol. 5, no. 5-6, pp. 243-254, 1986.

[11] J. Ahn, M. Lee, and H. Kwon, "Changes in respiratory quinone profiles of enhanced biological phosphorus removal activated sludge under different influent phosphorus/carbon ratio conditions," Bioprocess and Biosystems Engineering, vol. 29, no. 3, pp. 143-148, 2006.

[12] Irvan, Y. Atsuta, T. Saeki, H. Daimon, and K. Fujie, "Supercritical carbon dioxide extraction of ubiquinones and menaquinones from activated sludge," Journal of Chromatography A, vol. 1113, no. 1-2, pp. 14-19, 2006.

[13] M. Hanif, Y. Atsuta, K. Fujie, and H. Daimon, "Supercritical fluid extraction and ultra performance liquid chromatography of respiratory quinones for microbial community analysis in environmental and biological samples," Molecules, vol. 17, no. 3, pp. 2628-2642, 2012. 
[14] E. Iglesias Jiménez and V. Perez Garcia, "Evaluation of city refuse compost maturity: a review," Biological Wastes, vol. 27, no. 2, pp. 115-142, 1989.

[15] J. Tamaoka, Y. Katayama Fujimura, and H. Kuraishi, "Analysis of bacterial menaquinone mixtures by high performance liquid chromatography," Journal of Applied Bacteriology, vol. 54, no. 1, pp. 31-36, 1983.

[16] A. Kröger, "Determination of contents and redox states of ubiquinone and menaquinone," Methods in Enzymology, vol. 53, pp. 579-591, 1978.

[17] A. Hiraishi, Y. Yamanaka, and T. Narihiro, "Seasonal microbial community dynamics in a flowerpot-using personal composting system for disposal of household biowaste," Journal of General and Applied Microbiology, vol. 46, no. 3, pp. 133-146, 2000.

[18] X. Qian, G. Shen, Z. Wang et al., "Co-composting of livestock manure with rice straw: characterization and establishment of maturity evaluation system," Waste Management, vol. 34, no. 2, pp. 530-535, 2014.

[19] J.-C. Tang, T. Kanamori, Y. Inoue, T. Yasuta, S. Yoshida, and A. Katayama, "Changes in the microbial community structure during thermophilic composting of manure as detected by the quinone profile method," Process Biochemistry, vol. 39, no. 12, pp. 1999-2006, 2004.

[20] S. Goyal, S. K. Dhull, and K. K. Kapoor, "Chemical and biological changes during composting of different organic wastes and assessment of compost maturity," Bioresource Technology, vol. 96, no. 14, pp. 1584-1591, 2005.

[21] D.-L. Huang, G.-M. Zeng, C.-L. Feng et al., "Changes of microbial population structure related to lignin degradation during lignocellulosic waste composting," Bioresource Technology, vol. 101, no. 11, pp. 4062-4067, 2010.

[22] M. P. Bernal, A. F. Navarro, A. Roig, J. Cegarra, and D. García, "Carbon and nitrogen transformation during composting of sweet sorghum bagasse," Biology and Fertility of Soils, vol. 22, no. 1-2, pp. 141-148, 1996. 

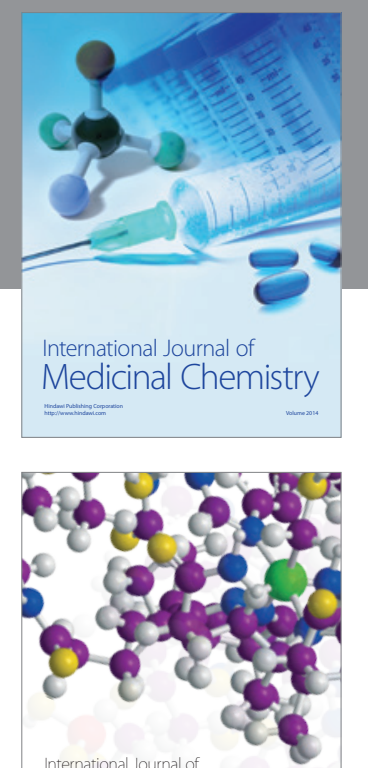

\section{Carbohydrate} Chemistry

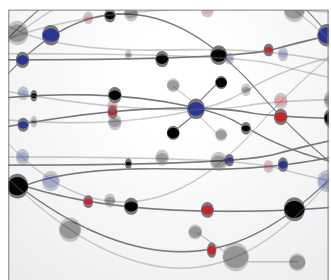

The Scientific World Journal
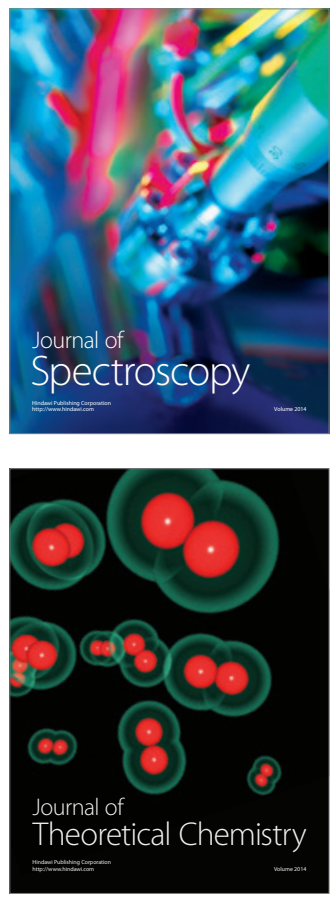
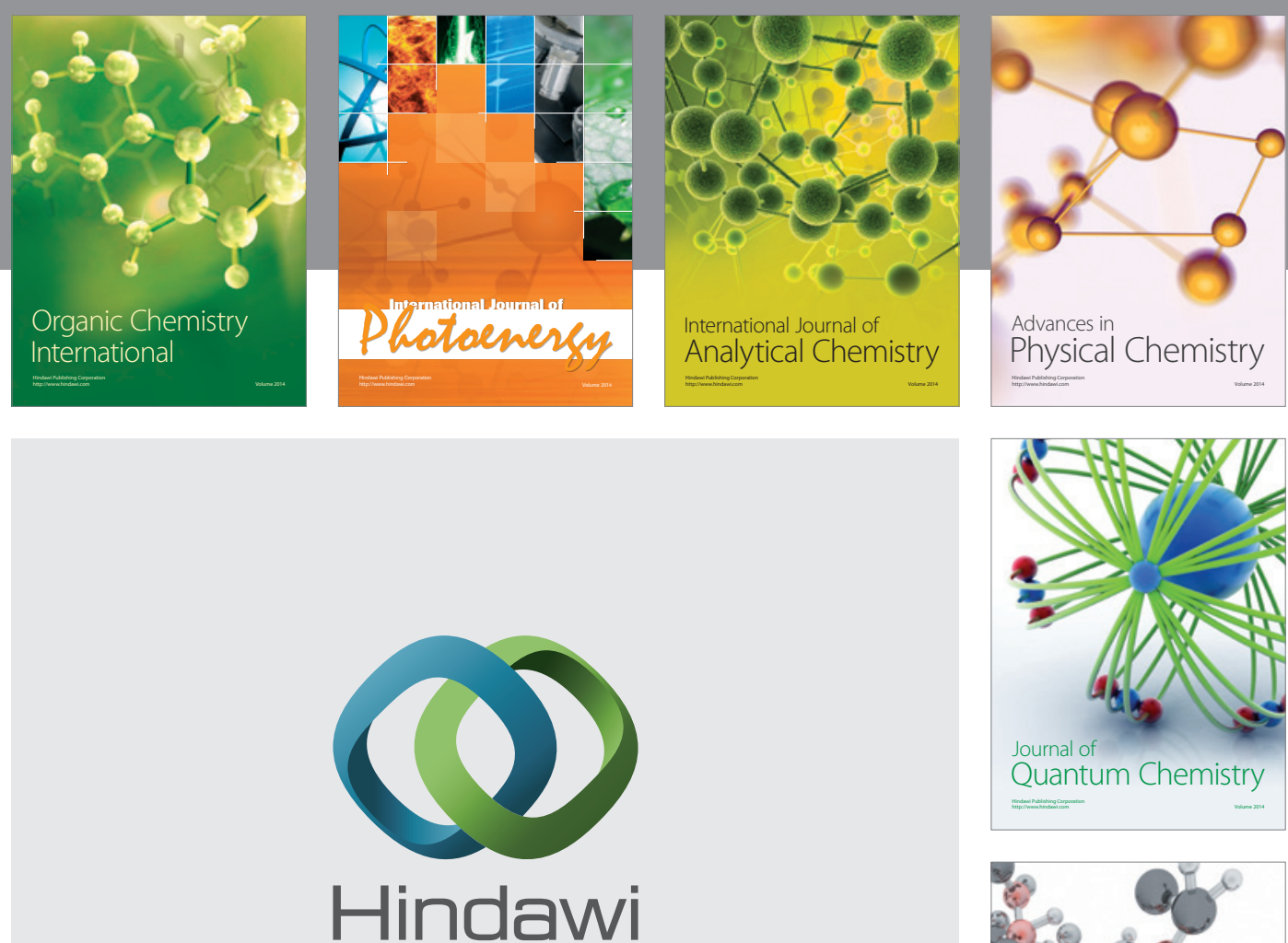

Submit your manuscripts at

http://www.hindawi.com

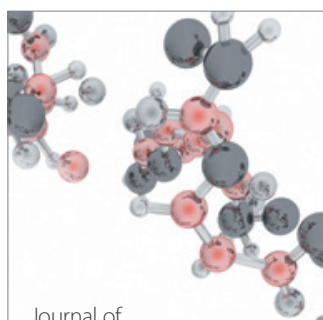

Analytical Methods

in Chemistry

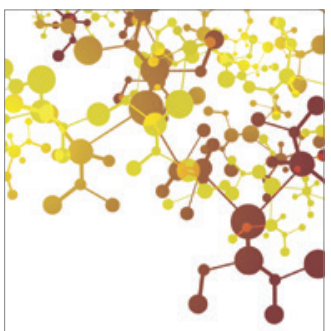

Journal of

Applied Chemistry

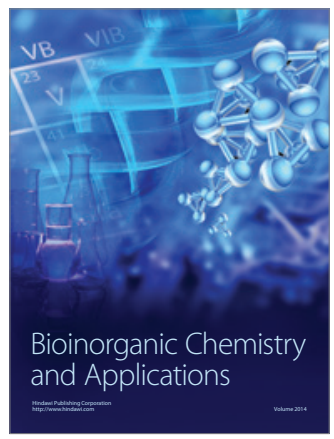

Inorganic Chemistry
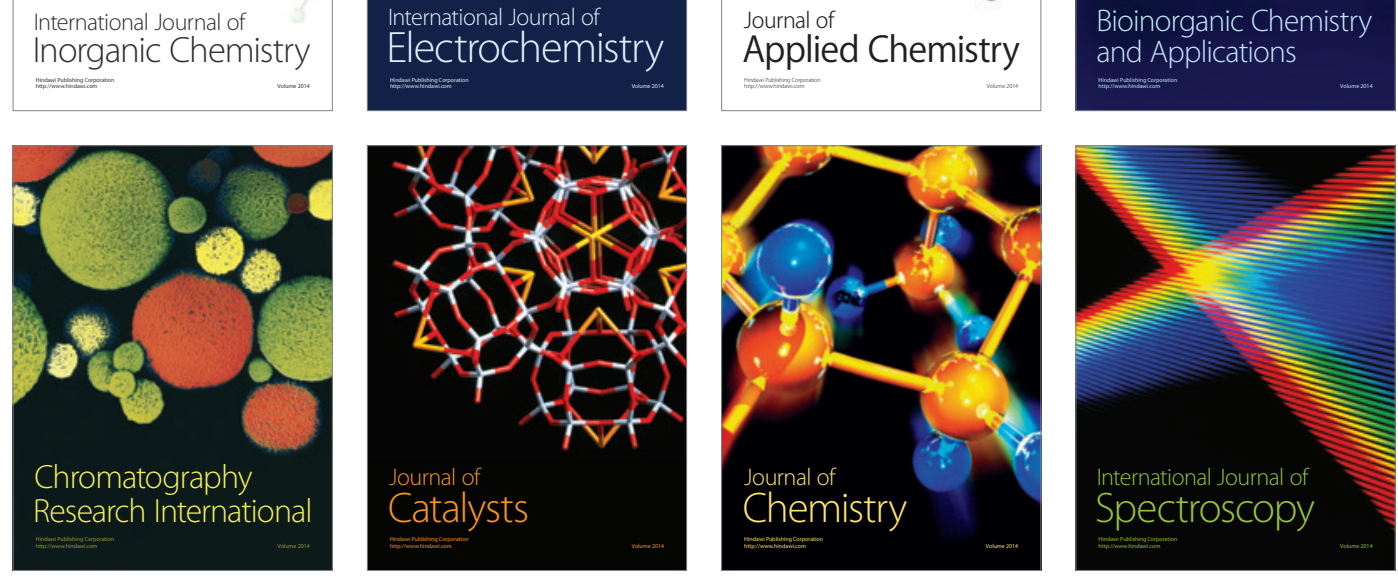